\title{
Modeling of professional mobility of a specialist in a military university
}

\author{
Alexey Korsakov, and Elena Lopanova* \\ Omsk Humanitarian Academy, 4 Chelyuskincev st., 2A, 644105 Omsk, Russia
}

\begin{abstract}
The technique of pedagogical modeling is reasonably considered in education as a promising direction of the development of theoretical and practical knowledge. Modeling involves not only the creation of a theoretically based model of future professional development, but also a practical justification, confirmation of the functioning of the created model. Modeling professional mobility of a future officer of a military university is of practical interest not only in the pedagogical field, but is also determined by the tasks of national development and national security of the Russian state in the short term. An unambiguous determination of the algorithm for the formation of all components of the professional mobility of a military specialist includes the development of personal and social professional mobility. The structure of the model, proposed in this article, was formed as a result of the generalization of modern theoretical knowledge, as well as experimental research, based on the leading military universities of Russia.
\end{abstract}

\section{Introduction}

The high rates of development of modern society impose dynamic changes in all areas of human life and activity. On the one hand, a person's capabilities for development are steadily growing, on the other hand, the lack of stability and rest determines the emergence of new conditions and requirements for the adaptive abilities of a person, requiring from him much higher adaptive potential. So, the entitative reality determines the development of new abilities and qualities of the individual. In turn, an individual with high adaptability sharply increases the ability to get used to the professional community, to successfully get used to it and work.

The most important integrative personal quality in the system of professionalism is professional mobility. The model of its creation under the conditions of a military university has key importance in the context of the modernization of the Russian army and the country's security system, as well as with the aim of training young qualified military personnel. According to the generally accepted definition, mobility should be understood as the rate and type of a person's reaction to changing external and internal circumstances, this is the ability to clearly respond to the rough and tumble of life.

A significant environment for a person's life is a professional occupation, in connection with which, the study and management of professional mobility, the mechanism of personal adaptability to the dynamism of the surrounding world as a personal trait, becomes relevant.

* Corresponding author: evlopanova@gmail.com 
Based on the research of L.V. Goryunova we distinguish three interrelated components of professional mobility: the first important component of professional mobility is internal motivation, the need for self-development and self-improvement of the individual; the second component is the individual's own pragmatist side of human behavior, which is realized through professional and life satisfaction in general; the third component is expressed in the ability to transform own living space and professional space around oneself, to improve it $[1]$.

The generalization of scientific approaches in the research of the last decade made it possible to determine several levels of the study of professional mobility [2]:

- the level of the individual's own qualities, which includes adaptive abilities, communication skills, social mobility, social memory, values and positions in the life of an individual, the presence of goals, the ability for self-development, self-knowledge;

- the level of the subject's activity, which is revealed through the manifestations in life and profession of the flexibility qualities, goal-setting, forecasting, sequence of actions, reflexivity;

- the level of ability for own development, self-improvement, transformation in a professional occupation, the external environment, in general, life. Professional mobility of an individual is considered from this perspective of a person trait, who is constantly dissatisfied with the results achieved and who is looking for sources of professional development in new areas and professions. The regularity of the search for the conclusions of the subjects at this level leads to training in new specialties, the choice of a new profession, an active search for a job, a change of place of residence, city.

\section{Materials and Methods}

In the theory and practice of the scientific world, the content of concepts is determined, the prerequisites and factors of the formation of professional mobility are determined, the conditions and the need for the development of this trait of future graduates are described, an analysis of professional mobility from the standpoint of a systemic integrative phenomenon is carried out. An important task of the research was to develop a model of occupational mobility. We propose to use the definition "model" to an understanding, close to V.M. Polonsky, where some other proposed object is identified with the model, copying the original example, created in order to study its structure, properties, functions, results of work or activity [3]. The model allows to reveal the hidden patterns of the training process, formation, to determine the interrelations and interdependencies between the components of the model structure, to create and test the influence of external and internal factors, to determine the influence of the socio-cultural environment, to study the parameters and criteria for measuring the effectiveness of actions. Another important property of modeling is the ability of detailed research with the possibility of multiple repetition and reproduction of the result in practice. Modern military pedagogy of higher education needs to solve complex processes of selection of cadets, the formation of their special personal qualities in order to obtain highly qualified military specialists and leaders. Pedagogical modeling is an actual mechanism for solving some of the important tasks of the system of higher education and special training.

There is an actual opinion of P.A. Sorokin, regarding the responsibility of the modern education system to ensure the socialization of the graduate's personality, to provide the opportunity to get knowledge, skills and abilities, that allow the graduate to be mobile, and in addition, to develop personal qualities, that help determine professional preferences, and in the future, adapt and successfully achieve professional potential [4].

The educational system is such, that the criterion for measuring professionalism, effective performance of professional tasks is the concept of competence. A graduate of a military 
university must have a strictly defined set of key professional competencies. With regard to the system of military education, a university graduate must be ready to demonstrate competence in practice in the operation of military weapons. The previous stage in the formation of this competence should be the formation of a clear understanding of the essence of employment activity as a profession. Ideas about the professional occupation of a military man should be as specificated as possible, bringing the understanding of the future profession to mastering a narrow focus. Of great importance in this system of competencies is the ability to determine one option from all possible, that is most precise in solving a work task. This is facilitated by the understanding of the object of the military professional field of activity, which includes many components, that form a single system: technical means and systems, weapons, technological equipment, personnel, fulfilling assigned military tasks.

Studying in a military university has a number of features, that were distinguished as a result of their own professional occupation and analysis of the work of specialists in the field of military education (A.V. Gladkova, S.I. Denisenko, O.A. Kozlova, M.A. Lyamzina, Yu.F. Mikhailova, A.A. Chervova, A.N. Yanuk, and others). We propose to include the following ones in the distinctive features of military higher education:

- the maximum proximity of the educational environment to the conditions of professional occupation in the future (on sentry duty, duty details, compliance with the manual, strict discipline, keeping regular hours in combination with the process of learning theoretical material). The constant shortage of free time creates a high pace of activity and a high level of physical and psychological stress, as a result, the requirements for health and personal qualities of cadets increase;

- strict professional hierarchism: training and education of cadets as a common soldier, which includes the first stage of the formation of basic knowledge, abilities and skills; training as a junior leader, which includes, in addition to the knowledge of the first stage, the ability to manage people, train and educate them, the ability to make simple discretionary decisions; the third stage of training is aimed at preparing the future head of the department, who must be able to clearly perform official tasks of a significant level in addition to the set of knowledge of the first two stages.

The specificity of the organization of the training process of cadets consists, in addition to the above-mentioned features, in the strict regulatory and legal regulation of the key training outcomes by the Federal State Educational Standard, as well as the combat manual and internal service regulations $[5,6]$. A set of standard regulations is aimed at developing both theoretical professional skills and practical professional skills in the field of the future military profession, which includes requirements for mastering complex technical systems.

The most important regulatory document, that determines the content, targets and results of the educational process is the Federal State Educational Standard for Military Education (FSES). This result is an independent competent officer, who is able to make better decisions and is capable of professional occupation at a given level immediately after completion of training.

The relevance of the Federal State Educational Standard for Military Education is determined by the following circumstances:

- the standard establishes high requirements for the level of training of military professionals, that meet the requirements of the time and the development of military science and technology. Takes into account the need for proficiency in automated communication systems and technical weapons of a modern army;

- contains guidelines for the formation of personal qualities of cadets of military universities, both as an independent professional unit and as a subject of activity in the context of the global humanistic development of the world; 
- sets the focus on the formation of the skill of solving professional military tasks, automating the decision-making process and responsibility for them, mastering the mechanism of constructing an algorithm of actions while drawing military duty;

- takes into account the shortage of time, accurately distributed between the theoretical and practical training of cadets, which is associated with the value of mastering the practical content of the military profession.

Analysis of work under the conditions of the Federal State Educational Standard of Higher Military Education allowed to identify problems in its implementation:

- the importance of concretizing the methodological apparatus, basic concepts and, in particular, the competence-based approach directly for the military education system;

- bad description of the organizational and managerial components of higher military education, methodological tools and recommendations for the use of the Federal State Educational Standard of Higher Education;

- low motivation of the teaching staff and the officers in the introduction and use of the Federal State Educational Standard of Higher Education in the practice of teaching cadets of a military university using new approaches to the educational process;

- bad professional support and preparedness of teachers of a military higher educational institution for introduction in practice, compliance with the requirements of the Federal State Educational Standard of Higher Education.

The leading goal of the educational process of a military university is the development of key personal and professional qualities of future officers in the process of mastering educational programs expressed in the Federal State Educational Standard in the list of competencies, offered for various areas (profiles) of cadets training [7, 8, 9].

In this situation, the formation and experimental testing of a model of the development of professional mobility of future officers is determined by the urgent need to solve the problem of improving the quality and level of training of qualified military specialists, corresponding to the modern military requirements of the state and society. The developed model takes into account the importance of moral and psychological support and pedagogical conditions, that contribute to the formation of professional mobility of cadets of the specialty "Legal support of national security".

\section{Results and Discussion}

The model of the development of professional mobility of cadets of a military university contains the determination of approaches, methods, means, components, subjects of interaction, stages, levels, indicators of the formation of professional mobility among cadets, as well as the results of experimental work $[10,11]$.

The modeling of the system of the development of professional mobility was carried out in compliance with the following methodological principles:

- the principle of a single, simultaneous and sequential formation of components of professional mobility;

- the principle of the unity of education and professional training of cadets in a military university;

- the principle of the development of a systems type of thinking, achieved through a high degree of interdisciplinary integration;

- the principle of combining the student's personal development with the need to comply with the requirements of the manual, where priority is given to the independence and harmony of the student;

- the principle of individualization of training cadets, which is expressed in taking into account individual characteristics, namely: interests, worldview, status in the group; 
- the principle of personal ambidexterity in the process of forming occupational mobility. The proposed model of professional mobility includes two groups of components: personal and social occupational mobility.

Personal mobility is understood as the activity of an individual, expressed in activity and aimed at satisfying the subject's need for new knowledge, which allows to quickly head for the changing conditions of the military profession and duty. Social mobility is defined as the active ability of a future officer to quickly adapt to a new place, type, and content of military duty.

The scheme of the model of professional mobility of a cadet of a military university is shown in Figure 1.
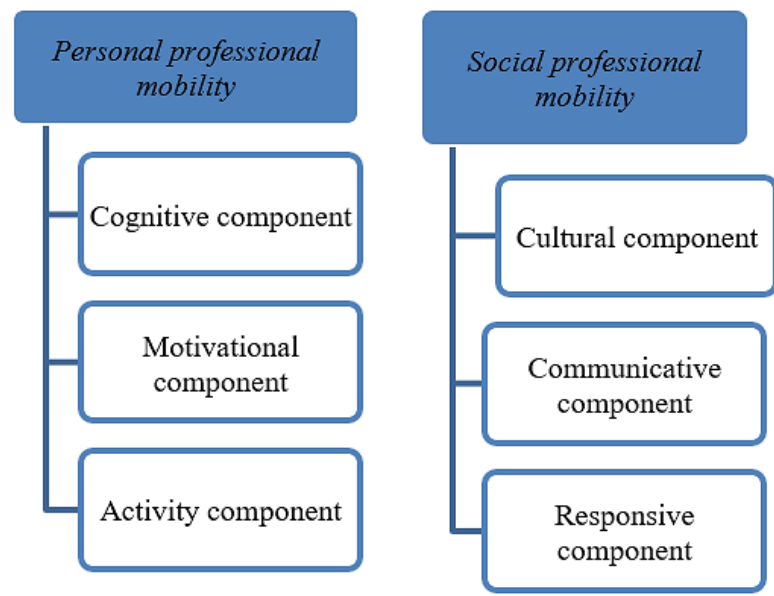

Fig. 1 Model of professional mobility of a graduate of a military university

The model scheme shows the components of two basic blocks of professional mobility of future officers. Personal mobility includes a cognitive component, that is responsible for the need for a military specialist's personality in self-improvement, expanding the range of knowledge in the field of professional occupation; the motivational component is more difficult to fill and is responsible for the independence of actions in the decision-making process, self-control, discipline, persistence in solving professional problems; activity-based reflects the ability to effectively plan own activities and the activities of others in the decision-making process, in the ability to follow the learned algorithm of logical actions while drawing military duty.

The structure of social mobility includes a cultural component - it is expressed in the ability to accept corporate values, norms and rules of behavior, as well as in moral, national, religious tolerance; the communicative component contains the ability to expand the range of professional contacts, the ability to build effective communication; the adaptive component consists of the readiness to quickly change the duty area and the ability to integrate into a new system of relations.

The process of forming the professional mobility of future officers is implemented at all stages of military education at the university and is divided into three parts:

- the 1st stage is aimed at the formation of theoretical general professional knowledge and is planned for 1-4 semesters;

- the 2nd stage is dedicated to the development of practical skills, based on the consolidation of theoretical material, 5-8 semesters;

- The 3rd stage of practical operational training is practically equated with professional military duty and includes 8-10 semesters. 
The proposed model goes through four stages of cadets' professional mobility formation: initial, basic, main and final. At each stage, the levels of professional mobility are formed (pre-professional, acceptable, constructive, productive).

\section{Conclusion}

As a result of experimental research and modeling of the pedagogical process, aimed at the formation of professional mobility, we succeeded to develop an optimal version of the model of the formation of professional mobility of cadets of a military university, to determine the necessary pedagogical conditions, to consider the stages of the formation of professional mobility and the levels of mastering the most important competencies, which together bring the desired result.

The initial stage of the formation of professional mobility is presented as the subject's getting knowledge at the pre-professional level. This level corresponds to the ability to apply a narrow horizon of experience in a standard situation using examples of activity. The values of professional development and motivation in military duty are not formed.

The basic stage can be characterized as the formation of unstable motivation and interest in certain academic subjects and fields of the profession of a military specialist. This stage is relevant to the allowable level of professional mobility formation and is expressed in the development and consolidation of the mechanism for carrying out activities as per sample, there is high rationality in the decision-making process and their validity is noted.

The main stage is expressed in the presence of cadets' value ideas and orientations about professional occupation, motivation in theoretical and practical training is steadily manifested, basic skills and abilities are formed, a high level of effectiveness of employment and educational activities. The main stage is relevant to the constructive level of development of professional mobility of cadets.

At the final stage, professional mobility is relevant to the productive level and is characterized as a moral certainty, high motivation for military activity, the ability to construct an independent algorithm of actions and decisions, the formation of work discipline, and a high level of personal interest in professional development and growth.

\section{References}

1. L.B. Goryunova, News of higher educational institutions, Volga region, 1, 63 (2007)

2. L.N. Korpachyova, E.V. Lopanova, E.P. Lopanova, International Journal of Innovation, Creativity and Change, 12(2) (2020)

3. Pedagogy technique, Scientific school of V. V. Kraevsky - V. M. Polonsky, Institute of Theory and History of Pedagogy: 1944-2014 (2014)

4. P. Lopanova, Social mobility, its forms and fluctuations, 647 (2002)

5. V.S. Lopanova, G.K. Artamonova, V.N. Lukin, I.A. Malyi, T.V. Musienko, Security in geopolitics: theoretical and methodological aspects, 268 (2017)

6. O.Yu. Akulov, Bulletin of the Tambov University, Series: Human sciences, 7(147), 35 (2015)

7. V.A. Belikov, P.Yu. Romanov, D.I. Pavlenko, A.M. Filippov, Perspectives of Science and Education, 1(43), 72 (2020)

8. A.M. Chukovsky, T.I. Chukovsky, Modern higher school: an innovative aspect, 122(48), 22 (2020)

9. A.S. Korsakov, V.A. Korsakov, A.N. Korsakov, World of science, culture, education, 2(81), 156 (2020) 
10. N.V. Yaroslavtseva, A.A. Yaroslavtseva, B.T. Tukhvatullin, A.Ch. Tukhvatullin, V.R. Nigamatulin, D.V. Levchenko, A.N. Levchenko, Prospects of science and education, 1(43), 10 (2020)

11. E.Yu. Gergalo, E.Ya. Gergalo, Materials of the research-to-practice conference, Ministry of Education and Science of the Russian Federation; Federal state budgetary educational institution of higher education "Siberian State Automobile and Highway Academy (SibADI)", 99 (2016)

12. N.P. Kalibernov, Military sociological aspects and trends of modernization of the Armed Forces of the Russian Federation, Materials of the military scientific conference, 194 (2017)

13. A.S. Rakityanskiy, S.Yu. Rakityanskiy, Implementation of the competence-based approach in the field of engineering training, 112 (2017) 